\title{
Translocation of protein kinase $C \delta$ contributes to the moderately high glucose-, but not hypoxia-induced proliferation in primary cultured human retinal endothelial cells
}

\author{
ZHAO-CHUN LIU ${ }^{1}$, EN-HONG YU ${ }^{1}$, WEI LIU ${ }^{1}$, XIAO-CHANG LIU ${ }^{1}$, \\ SHI-BO TANG ${ }^{2}$ and BANG-HAO ZHU ${ }^{1}$ \\ ${ }^{1}$ Department of Pharmacology, Cardiac and Cerebral Vascular Research Center, Zhongshan School of Medicine; \\ ${ }^{2}$ Zhongshan Ophthalmic Center, Sun Yat-Sen University, Guangzhou, Guangdong 510080, P.R. China \\ Received July 1, 2013; Accepted February 10, 2014
}

DOI: $10.3892 / \mathrm{mmr} .2014 .2049$

\begin{abstract}
Diabetic retinopathy is one of the most common complications in patients with diabetes and affects $\sim 75 \%$ of them within 15 years of the onset of the disease. Activation of protein kinase $\mathrm{C}$ (PKC) is a key feature of diabetes mellitus and may be involved in the pathogenesis of diabetic retinopathy. The present study aimed to examine the translocation of protein kinase $\mathrm{C}$ (PKC) isoforms, which are triggered by high an moderately high glucose levels as well as hypoxic conditions. The underlying cell mechanisms of PKC translocation in primary cultured human retinal endothelial cells (HRECs) were also investigated. The expression levels of PKC isoforms were assessed using western blot analysis. Cell proliferation was determined using the MTT assay and DNA synthesis was assessed by bromodeoxyuridine incorporation. Translocation of PKC isoforms was examined by western blot analysis and immunofluorescence. The expression of PKC $\alpha, \beta \mathrm{I}, \beta \mathrm{II}, \delta$ and $\varepsilon$ was detected, while PKC $\zeta$ was not detected in HRECs. The results of the present study were consistent with the findings of a previous study by our group, reporting that moderately high glucose levels and hypoxia, but not high glucose levels, significantly increased cell proliferation. It was demonstrated that the PKC $\delta$ isoform was translocated from the cytosol to the membrane only under moderately high glucose conditions, while PKC $\alpha$ and $\varepsilon$ isoforms were translocated from the cytosol to the membrane at high glucose conditions. In addition, PKC $\beta$ I was translocated under all three conditions. Translocation of PKC $\beta$ II was comparable among all groups. Furthermore, rottlerin, an inhibitor of PKC $\delta$, blocked cell
\end{abstract}

Correspondence to: Professor Bang-Hao Zhu, Department of Pharmacology, Cardiac and Cerebral Vascular Research Center, Zhongshan School of Medicine, Sun Yat-Sen University, 74 Zhongshan 2 Rd, Guangzhou, Guangdong 510080, P.R. China E-mail: zhubh@mail.sysu.edu.cn

Key words: human retinal endothelial cells, proliferation, protein kinase $\mathrm{C}$ isoforms, translocation, high glucose, hypoxia proliferation, which was induced by moderately high glucose levels, but not by hypoxia. Ro32-0432, an inhibitor of PKC $\alpha, \beta \mathrm{I}$ and $\varepsilon$, did not significantly affect proliferation of HRECs in all treatment groups. In conclusion, the present study suggested that PKC $\alpha, \beta \mathrm{I}, \beta \mathrm{II}, \delta$ and $\varepsilon$ were expressed in primary cultured HRECs, whereas PKC $\zeta$ was not. Cell proliferation induced by moderately high glucose concentrations was associated with translocation of the PKC $\delta$ isoform; however, hypoxic conditions did not induce translocation.

\section{Introduction}

Diabetic retinopathy is one of the most common complications in patients with diabetes and affects $\sim 75 \%$ of them within 15 years of disease onset. In a number of patients, diabetic retinopathy may progress into proliferative retinopathy, which is characterized by the growth of new blood vessels on the surface of the retina. Hyperglycemia is the primary pathogenic factor in the development of diabetic complications (1). Retinal capillary damage from high glucose-induced pericyte loss and alterations in retinal hemodynamics results in a hypoxic state in the early and late stages of diabetic retinopathy $(2,3)$. It has been previously established that the signaling effects of hyperglycemia and hypoxia contribute to the progression of diabetic retinopathy (4).

The activation of protein kinase $\mathrm{C}(\mathrm{PKC})$ is a key feature of diabetes mellitus. PKC translocation to the plasma membrane is considered as a hallmark of PKC activation and is frequently used to measure PKC isoform activation in cells. Increased PKC activation has been associated with changes in blood flow, basement membrane thickening, extracellular matrix expansion, increases in vascular permeability and abnormal angiogenesis, and has been implicated in the pathogenesis of diabetic retinopathy (5). PKC is a complex serine/threonine kinase family. At present, three groups and 12 isoforms of PKC have been determined in the following types of tissue: i) Classic or typical PKCs, including $\alpha, \beta I, \beta I I$ and $\gamma$, which are calcium- and diacylglycerol (DAG)-dependent; ii) novel PKCs, including $\delta, \varepsilon, \eta$ and $\theta$, which are calcium-independent and DAG-dependent; and iii) atypical PKCs, including $\zeta$ and $t / \lambda$, which are calcium and DAG-independent and are only activated 
by phosphatidylserine (6). The distribution of different PKC isoforms is commonly tissue- and species-dependent. In addition, various types of PKC isoforms may be expressed in the same cells, but with distinct biological functions. Alterations in the activities of distinct PKC isoforms have been linked to the development of macro- and microvascular complications observed in patients with diabetes (7). In bovine retinal endothelial cells, PKC $\alpha, \beta \mathrm{I}, \beta \mathrm{II}, \delta, \varepsilon$ and $\zeta$, representing all of the three PKC subgroups, have been detected (8). However, in primary cultured human retinal endothelial cells (HRECs) the distribution of PKC isoforms has not been fully elucidated. Furthermore, the association between translocation of PKC isoforms and proliferation of HRECs remains to be elucidated.

The results of a previous study by our group identified a significant increase in the proliferation of HRECs at moderately high glucose concentrations and hypoxic conditions (9). Notably, high glucose concentrations alone did not significantly induce proliferation of HRECs. Therefore, the present study aimed to examine the subcellular distribution of PKC isoforms in cultured HRECs and analyze the translocation of PKC isoforms under the abovementioned glucose and hypoxic conditions.

\section{Materials and methods}

Culture of HRECs. HRECs were isolated from tissue a patient undergoing corneal transfer surgery at Zhongshan Ophthalmic Center, Sun Yat-Sen University (Guangzhou, China) as previously described (10). Briefly, cells were grown in human endothelial serum free-medium (Gibco-BRL, Carlsbad, CA, USA) supplemented with $10 \%$ fetal bovine serum (Thermo Fisher Scientific, Hyclone, Logan, UT, USA), $5 \mu \mathrm{g} / 1$ $\beta$-endothelial cell growth factor $(\beta$-ECGF; R\&D Systems Inc., Minneapolis, MN, USA) and $1 \%(\mathrm{v} / \mathrm{v})$ penicillin-streptomycin (Gibco-BRL, Grand Island, NY, USA) at $37^{\circ} \mathrm{C}$ in a $5 \% \mathrm{CO}_{2}$ and $95 \%$ air atmosphere. Cells were digested with Trypsinase-EDTA (Sigma-Aldrich, St. Louis, MO, USA) and subcultured in $25 \mathrm{~cm}^{2}$ culture flasks for cell fractionation or 96-well plates for proliferation assay under the appropriate assay conditions. The number of live cells were counted using a blood counting instrument (Buerker; Brand $\mathrm{GmbH}$ and Co. KG, Wertheim, Germany) following $0.4 \%$ trypan blue staining. Cells at passages three to six were used in the experiments. The experiments adhered to the tenets of the Declaration of Helsinki for research involving human subjects. Ethical approval was obtained from the Ethics Committee of Zhongshan Ophthalmic Center and informed consent was obtained from all the donor patient.

HREC proliferation assay. HRECs were trypsinized (trypsinase-EDTA) and seeded in 96-well plates $(\sim 5,000$ cells/well). Following overnight incubation, cells were transferred into serum-free medium (without $\beta$-ECGF) and were further incubated for $24 \mathrm{~h}$. The medium was then replaced with growth medium and cells were further incubated under one of the following conditions for an additional $48 \mathrm{~h}$ : normal glucose concentration [5 mM D-glucose (Sigma-Aldrich; control group)]; moderately high glucose (15 mM D-glucose; MG group); high glucose (30 mM D-glucose; HG group); $150 \mu \mathrm{M} \mathrm{CoCl}_{2}$ (Sigma-Aldrich; HO group), which is known to trigger chemical hypoxia in cells, and with or without rottlerin (10 $\mu \mathrm{M}$; Santa Cruz Biotechnology, Inc., Santa Cruz, CA, USA; RO group) or Ro 32-0432 (200 nM; Calbiochem, La Jolla, CA, USA; Ro32 group). Equal molar ratios of mannitol (Sigma-Aldrich) were used as an osmotic control: $15 \mathrm{mM}$ D-mannitol (MM group) and $30 \mathrm{mM}$ D-mannitol (HM group). For quantitative analysis of cell viability, $10 \mu \mathrm{l}$ of a cell counting MTT solution (Sigma, St. Louis, MO, USA) was added to each well and incubated for $4 \mathrm{~h}$ at $37^{\circ} \mathrm{C}$ in a humidified $\mathrm{CO}_{2}$ incubator. Absorbance at $490 \mathrm{~nm}$ was measured with a microplate reader (BioTek Instruments, Inc., Winooski, VT, USA). Bromodeoxyuridine (BrdU) reagent (BrdU Cell Proliferation Assay kit; Millipore, Bedford, MA, USA) was diluted to $60 \mu \mathrm{M}$ and added into the wells $24 \mathrm{~h}$ following treatment of the cells under the various conditions. Following incubation, absorbance was measured at $450 \mathrm{~nm}$.

\section{Cell fractionation.}

Whole cell lysates. HRECs were washed twice with ice-cold phosphate-buffered saline (PBS) and lysed in western and immunoprecipitation cell lysis buffer (Beyotime, Shanghai, China) with 1 mmol $\mathrm{Na}_{3} \mathrm{VO}_{4}, 1 \mathrm{mmol} \mathrm{NaF}$ (Sigma-Aldrich) and Protease Inhibitor Cocktail Set ${ }^{\circledR}$ (Calbiochem, Darmstadt, Germany), and incubated for $30 \mathrm{~min}$ on ice then centrifuged at $15,000 \mathrm{x} \mathrm{g}$ for $15 \mathrm{~min}$ at $4^{\circ} \mathrm{C}$. The supernatants were collected.

Subcellular lysates. HREC lysates were subfractionated into cytosolic and membrane fractions by adapting the methods previously described (11). Briefly, HRECs were washed twice with ice-cold PBS, scraped in lysis buffer A [1 $\mathrm{mM} \mathrm{NaHCO} 3,5 \mathrm{mM} \mathrm{MgCl}{ }_{2} \cdot 6 \mathrm{H}_{2} \mathrm{O}, 50 \mathrm{mM}$ Tris- $\mathrm{HCl}$, $10 \mathrm{mM}$ ethylene glycol tetraacetic acid, $2 \mathrm{mM}$ EDTA, $500 \mu \mathrm{M}$ 4-(2-aminoethyl)-benzenesulfonyl fluoride, $150 \mathrm{nM}$ aprotinin, $1 \mu \mathrm{M}$ leupeptin, $1 \mu \mathrm{M}$ E-46 protease inhibitor] at $4^{\circ} \mathrm{C}$, homogenized by passing through a 26 gauge needle five times, incubated for $15 \mathrm{~min}$ on ice and ultracentrifuged at $100,000 \times \mathrm{g}$ for $1 \mathrm{~h}$ at $4^{\circ} \mathrm{C}$. The supernatant provided the cytosolic fraction. The pellet was resuspended in buffer B (buffer A with 1\% Triton X-100), homogenized by passing through a 26 gauge needle five times, incubated for $15 \mathrm{~min}$ on ice and ultracentrifuged at $100,000 \mathrm{x} \mathrm{g}$ for $1 \mathrm{~h}$ at $4^{\circ} \mathrm{C}$. The supernatant provided the membrane fraction. The protein concentration in all samples were determined by the Bicinchoninic Acid Protein Assay kit (Beyotime Institute of Biotechnology, Shanghai, China) using bovine serum albumin (BSA) as the standard.

Western blot analysis. Equal amounts of protein from cell lysates (20-80 $\mu \mathrm{g})$ or cell fractions of the different treatment groups, along with appropriate molecular size standards and the rat brain positive control were separated using 8\% SDS-PAGE and blotted onto a polyvinylidene fluoride membrane (Millipore, Billerica, MA, USA) for $1.5 \mathrm{~h}$ at $100 \mathrm{~V}$ using a Bio-Rad transblot apparatus (Bio-Rad, Hercules, CA, USA). The membrane was blocked for $2 \mathrm{~h}$ at room temperature with tris-buffered saline with Tween 20 (TBST) containing $5 \%$ fat-free milk. Following three washes with TBST, the membrane was incubated overnight at $4^{\circ} \mathrm{C}$ with anti-PKC $\beta \mathrm{I}$, $\beta I I$ (1:200; Santa Cruz Biotechnology, Inc., Dallas, TX, USA), 
anti-PKC $\alpha, \delta, \varepsilon$ and $\zeta[1: 1,000$, Cell Signaling Technology, Danvers, MA, USA], anti- $\beta$-actin (1:2,000; $\beta$-actin was used as the loading control of the cytosolic fraction; Cell Signaling Technology) anti- $\mathrm{Na}^{+}-\mathrm{K}^{+}$-ATPase $\left(1: 500, \mathrm{Na}^{+}-\mathrm{K}^{+}\right.$-ATPase was used as the loading control of the membrane fraction; Cell Signaling Technology) in 5\% fat-free milk or 5\% (BSA). The membrane was then washed with TBST and incubated for $1.5 \mathrm{~h}$ at room temperature with a horseradish peroxidase (HRP)-labeled anti-mouse immunoglobulin G (IgG; 1:2,000, Cell Signaling Technology) or HRP-labeled anti-rabbit IgG (1:2,000; Invitrogen Life Technologies, Carlsbad, CA, USA). Antigen detection was performed with an enhanced chemiluminescence detection system (Cell Signaling Technology).

Immunofluorescence labeling and confocal microscopy. HRECs were plated in six-well plates with a coverslip over each well and incubated in growth medium. Following overnight incubation, cells were transferred into a serum-free medium and incubated for $24 \mathrm{~h}$. The medium was then replaced with different growth media, including normal glucose $(5 \mathrm{mM}$ D-glucose), moderately high glucose (15 mM D-glucose), high glucose (30 mM D-glucose) and $150 \mu \mathrm{M} \mathrm{CoCl}_{2}$ and incubated for $48 \mathrm{~h}$. The cells were then washed twice with ice-cold PBS, fixed with $3.7 \%$ formaldehyde for $15 \mathrm{~min}$ at room temperature and the membranes were permeabilized with $0.1 \%$ Triton X-100 for 5 min. Cells were washed three times with PBS and blocked with $1 \%$ goat serum plus $0.1 \%$ BSA in PBS for $1 \mathrm{~h}$ at room temperature. Antibodies for immunoblotting were diluted at 1:100 in blocking solution, added to each coverslip and incubated for $1 \mathrm{~h}$ at $37^{\circ} \mathrm{C}$. Following washing three times with TBST, the secondary fluorescein isothiocyanate-conjugated antibody was diluted at 1:200 in blocking solution, added to each coverslip, incubated for $1 \mathrm{~h}$ at $37^{\circ} \mathrm{C}$ in the dark and washed three times with TBST. A confocal laser scanning image system (FV500; Olympus, Tokyo, Japan) was used to detect immunofluorescence.

Statistical analysis. All experiments were performed in triplicate. Results are expressed as the mean \pm standard deviation. One-way analysis of variance was used to analyze all data and the multiple comparisons were conducted by Tukey's test. $\mathrm{P}<0.05$ was considered to indicate a statistically significant difference.

\section{Results}

Expression of PKC isoforms in HRECs. As shown in Fig. 1, PKC isoforms were detected by immunoblotting from total cell lysate of primary cultured HRECs. The expression of PKC $\alpha$ $(80 \mathrm{kDa}), \beta \mathrm{I}(79 \mathrm{kDa}), \beta \mathrm{II}(80 \mathrm{kDa}), \delta(78 \mathrm{kDa})$ and $\varepsilon(82 \mathrm{kDa})$ was identified, whereas expression of PKC $\xi(78 \mathrm{kDa})$ was not identified in the HRECs.

Proliferation of HRECs under different conditions. Consistent with the results of a previous study conducted by our group, the MTT assay demonstrated that moderately high glucose concentrations and hypoxia conditions $\left(150 \mu \mathrm{M} \mathrm{CoCl}_{2}\right)$ significantly induced proliferation of HRECs as compared with HREC proliferation in the control group. However, high glucose concentrations alone did not significantly induce cell proliferation (Fig. 2).
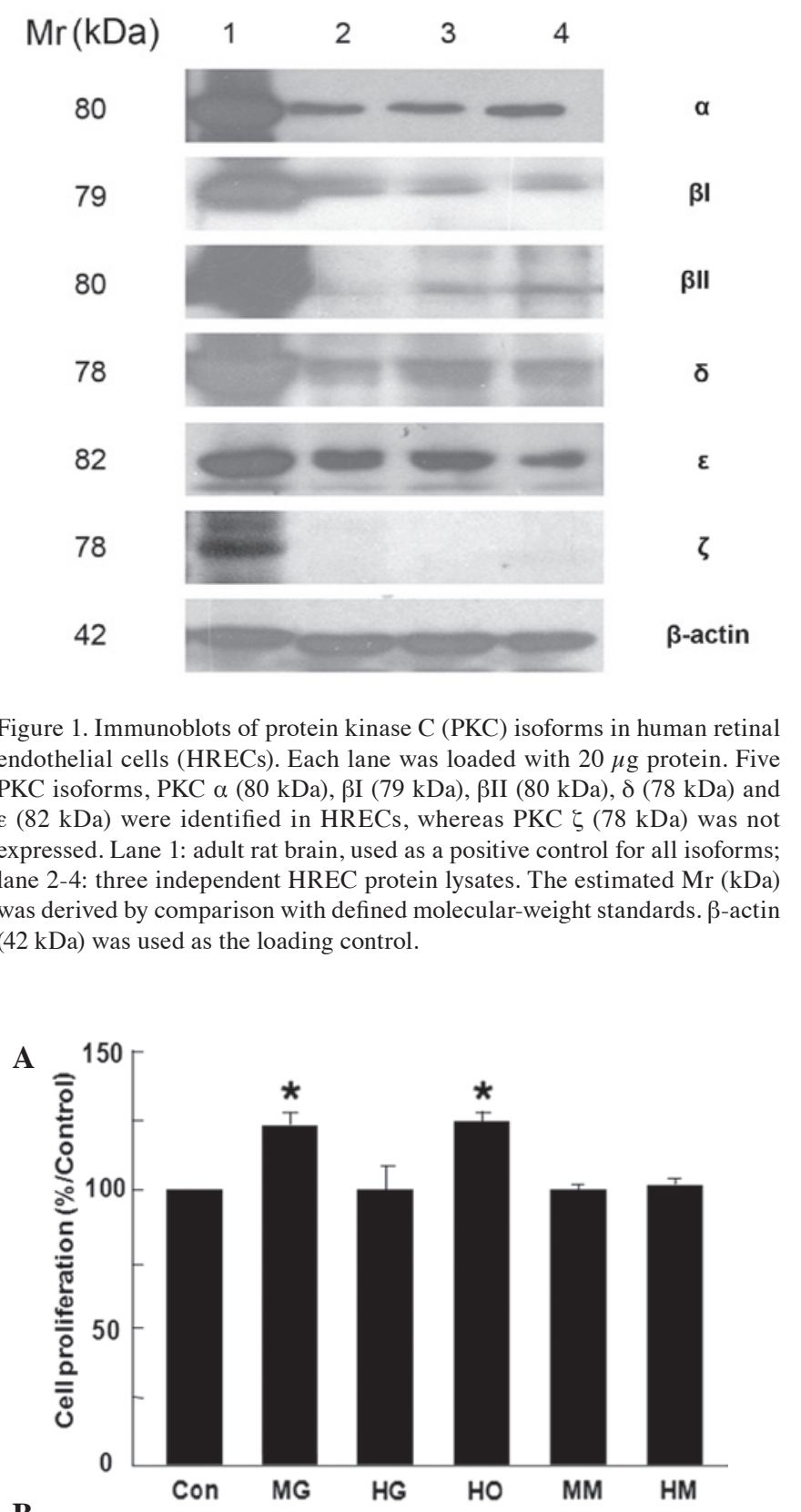

$\mathbf{B}$

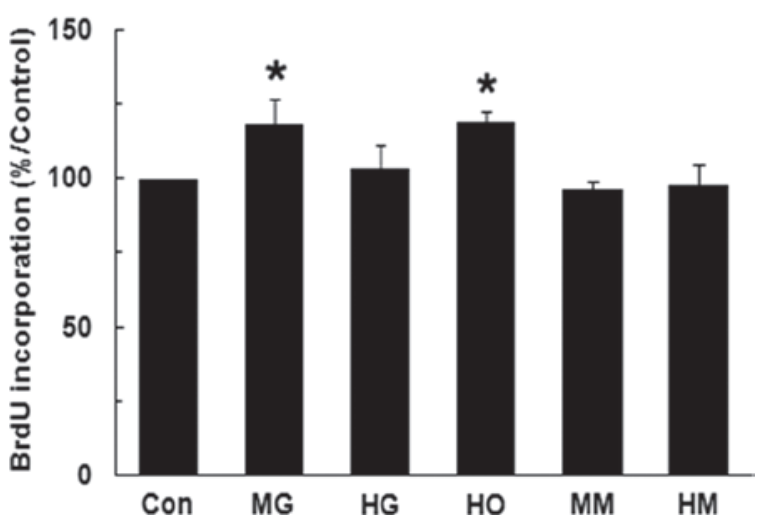

Figure 2. HREC proliferation and DNA synthesis following $48 \mathrm{~h}$ of treatment at normal glucose (5 mM, Con), moderately high glucose (15 mM, MG), high glucose (30 mM, HG) and hypoxia (150 $\left.\mu \mathrm{M} \mathrm{CoCl}_{2}, \mathrm{HO}\right)$ conditions. Equal molar concentrations of mannitol were used for osmotic control; MM, 15 mM D-mannitol; and HM, 30 mM D-mannitol. (A) Cell proliferation was assessed using the MTT assay. (B) DNA synthesis was measured as BrdU incorporation. Data are expressed as the mean \pm standard deviation and the average of four independent experiments. ${ }^{*} \mathrm{P}<0.05$ vs. control. BrdU, bromodeoxyuridine; HREC, human retinal endothelial cell. 
$\mathbf{A}$

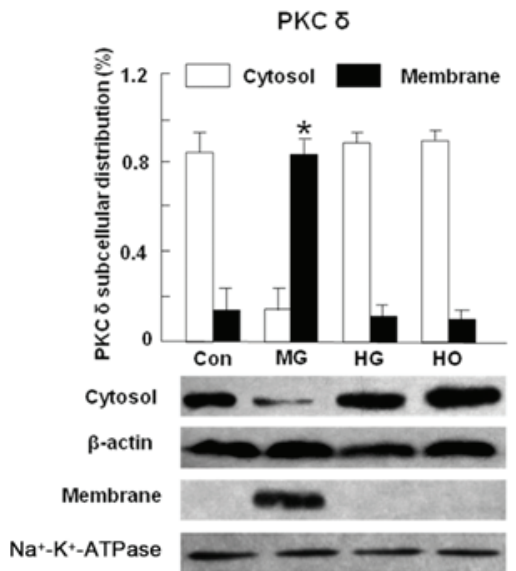

PKC $\beta I$

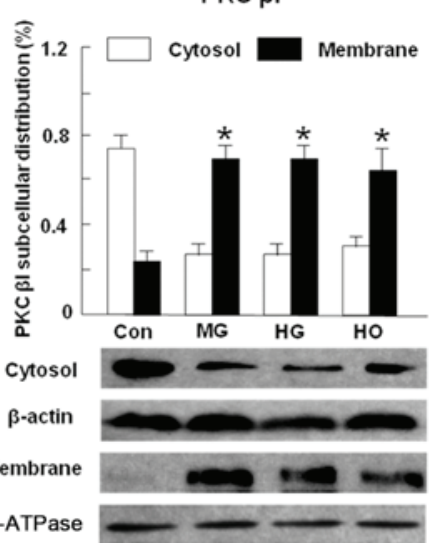

PKC a

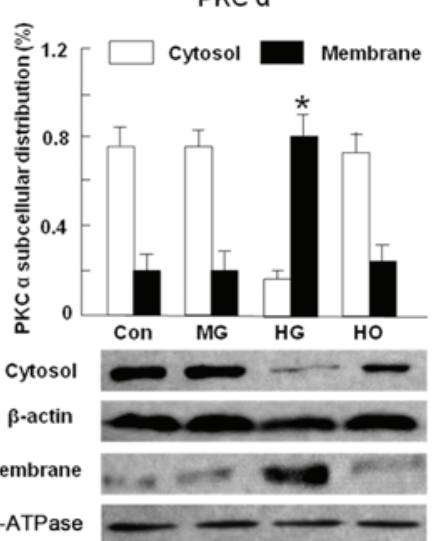

PKC $\beta I I$

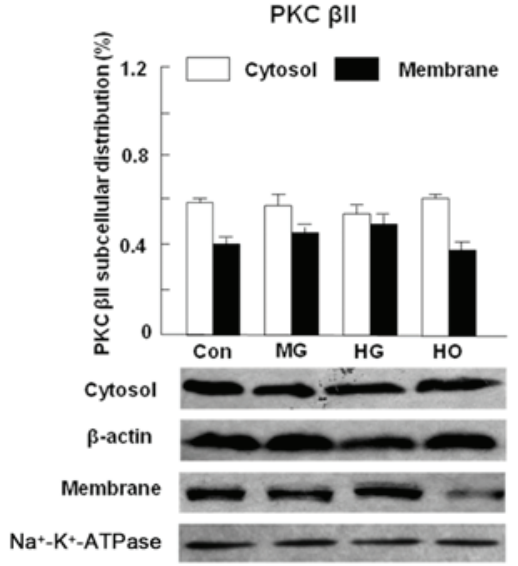

PKC \&

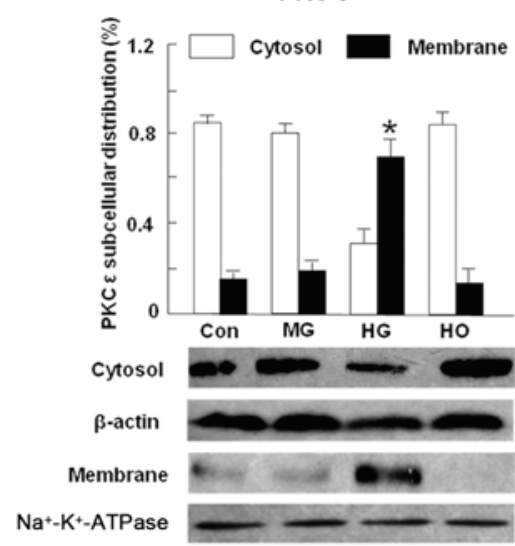

B

Con

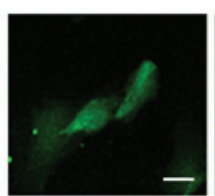

PKC a

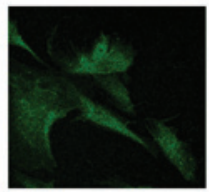

PKC \&
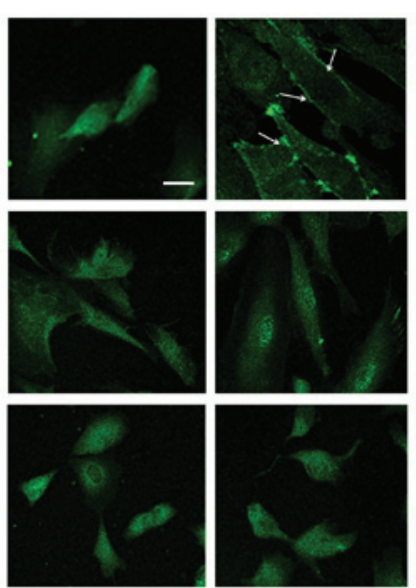

PKC $\beta I$
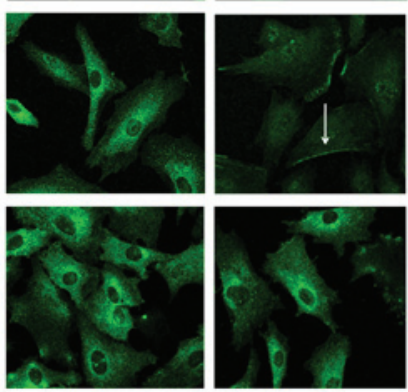

PKC $\beta$ II

HG

HO
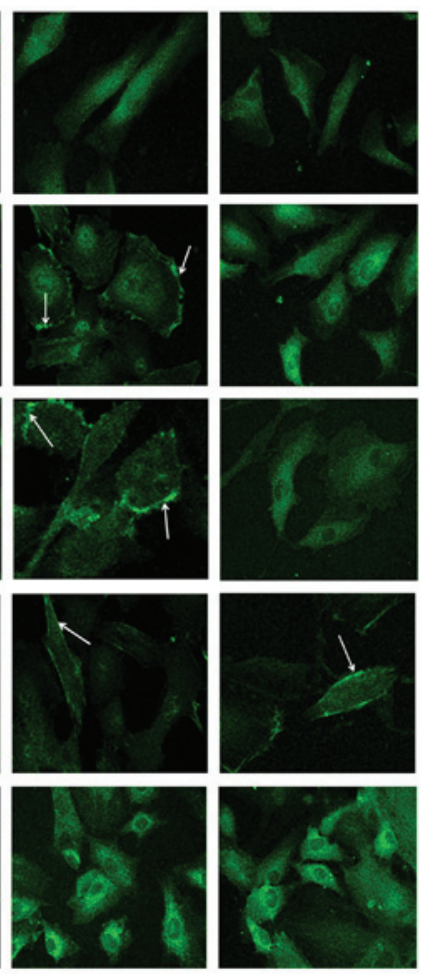

Figure 3. PKC isoform distributions in HRECs treated at normal glucose (5 mM, Con), moderately high glucose (15 mM, MG), high glucose (30 mM, HG) and hypoxia (150 $\left.\mu \mathrm{M} \mathrm{CoCl}_{2}, \mathrm{HO}\right)$ conditions. (A) Western blot analysis of PKC isoform distributions in HRECs incubated at different conditions for $48 \mathrm{~h}$. $\beta$-actin was used as the loading control. Data are expressed as the mean \pm standard deviation from three independent experiments. " $\mathrm{P}<0.05$ vs. control. (B) Immunofluorescence imaging of PKC isoforms in HRECs treated at different conditions for $48 \mathrm{~h}$. White arrowheads denote PKC translocation to the membrane. Scale bar, $20 \mu \mathrm{m}$. Original magnification, x400. PKC, Protein kinase C; HREC, human retinal endothelial cell; ATPase, adenosinetriphosphatase. 
A

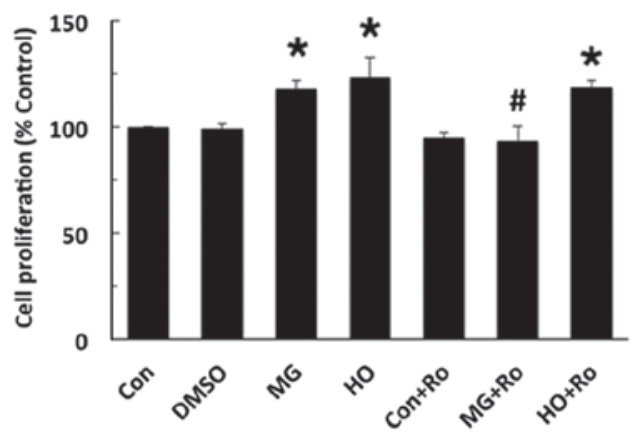

C

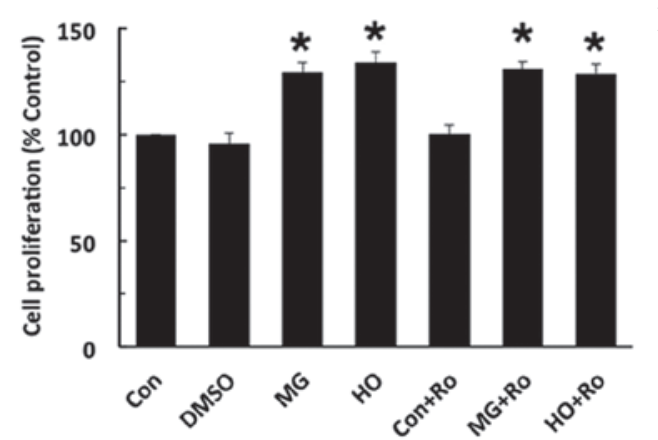

B

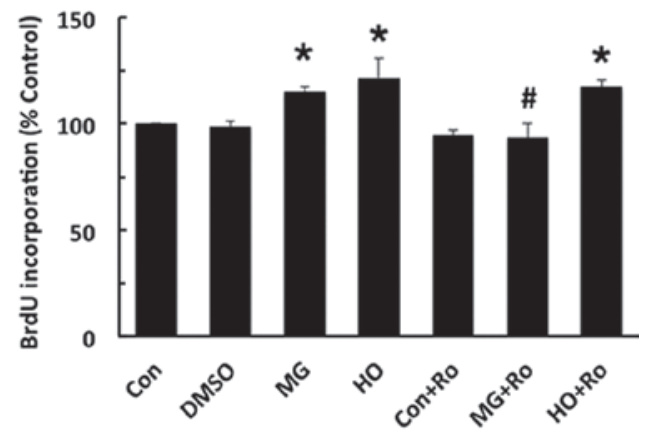

D

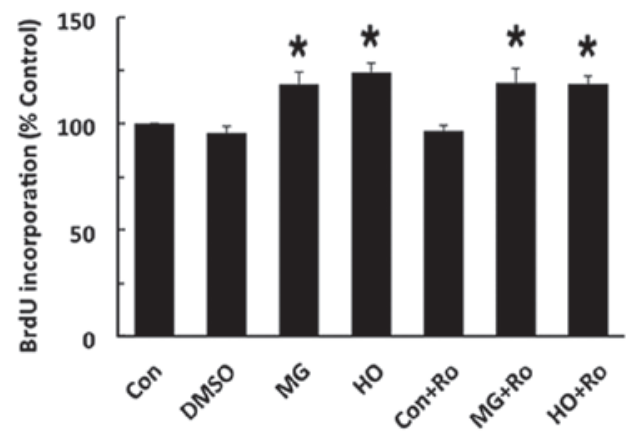

Figure 4. Effects of rottlerin or Ro32-0432 on HREC proliferation and DNA synthesis. HRECs were treated under different conditions for $48 \mathrm{~h}$ with or without rottlerin (Ro, $10 \mu \mathrm{M})$ or Ro32-0432 (Ro32, $200 \mathrm{nM}$ ) in either normal glucose (5 mM, Con), moderately high glucose (15 mM, MG), high glucose (30 mM, HG) and hypoxia (150 $\left.\mu \mathrm{M} \mathrm{CoCl}_{2}, \mathrm{HO}\right)$ conditions. Equal amounts of DMSO were used as the vehicle control in all groups except the control group. (A) Effects of rottlerin on cell proliferation was measured by the MTT assay. (B) Effect of rottlerin on DNA synthesis was measured as BrdU incorporation. (C) Effects of Ro32-0432 on cell proliferation was measured by the MTT assay. (D) Effect of Ro32-0432 on DNA synthesis was measured as BrdU incorporation. Data are expressed as the mean \pm standard deviation from four independent experiments. "P<0.05 vs. DMSO and ${ }^{\#} \mathrm{P}<0.05$ vs. MG group. HREC, human retinal endothelial cell; DMSO, dimethylsulfoxide; BrdU, bromodeoxyuridine.

Translocation of PKC isoforms under different conditions. As shown in Fig. 3A, PKC isoform translocation was identified in the moderately high glucose, high glucose and hypoxia treated groups. PKC $\delta$ was significantly translocated from the cytosol to the membrane in the moderately high glucose group $(\mathrm{P}<0.05)$; whereas PKC $\alpha$ and $\varepsilon$ were significantly translocated from the cytosol to the membrane in the high glucose group. PKC $\beta$ I and $\beta$ II were translocated under all treatment conditions. In the control group, western blot analysis of the HRECs showed partial translocation to the membrane. Using confocal fluorescence imaging, the immunofluorescence intensity of translocated PKC isoforms were enhanced, suggesting an activation pattern for all of these isoforms (Fig. 3B).

Effects of rottlerin and Ro 32-0432 on cell proliferation. Rottlerin has a high affinity for PKC $\delta\left(\mathrm{IC}_{50} 3-6 \mu \mathrm{M}\right)$. It has also been reported to inhibit other isoforms of PKC in addition to PKC $\delta$, but at a concentration of $>30 \mu \mathrm{M}$. By contrast, previous studies have demonstrated that rottlerin inhibited PKC $\delta$ at $<10 \mu \mathrm{M}(12-15)$. The present study identified that rottlerin prevented cell proliferation triggered at moderately high glucose conditions (Fig. 4A and B). However, rottlerin did not elicit any effects on cell proliferation induced by hypoxic conditions or proliferation under normal glucose concentrations. Previous studies have found that Ro32-0432, at a concentration of $200 \mathrm{nM}$, exerts inhibitory effects on PKC $\alpha, \beta$ and $\varepsilon(16,17)$; however, no significant inhibition of cell proliferation was observed in the present study (Fig. 4C and D).

\section{Discussion}

The present study focused on the effects of high glucose and hypoxic conditions on cell proliferation, as these stimuli are considered to be relevant in the initiation and progression of diabetic retinopathy and other ischemic retinopathies. In previous studies on diabetes, $25-30 \mathrm{mM}$ is the most commonly employed glucose concentration in cell models; however, in the present study a moderately high glucose $(15 \mathrm{mM})$ concentration was used, which may be closer to the clinic situation (18), regarding the particularity of primary HRECs. An incubation time of $48 \mathrm{~h}$ was selected in consideration of the cell growth cycle. It was identified that these primary HRECs progressed into the exponential phase $\sim 12-24 \mathrm{~h}$ following cell passage. This phase lasted $\sim 48-60 \mathrm{~h}$ prior to the cells entering the silent phase.

Primary cultured HRECs were employed in the present study in order to reflect the clinic situation. Previous studies using HRECs, but not other endothelial cells, have obtained similar results to those of the present study. Premanand et al (19) failed to identify an increase in cell proliferation following high glucose $(30 \mathrm{mM})$ exposure in HRECs, despite observing an increased expression of vascular endothelial growth factor (VEGF). This finding is consistent with the results of the present study indicating cell proliferation under high glucose 
(30 mM) conditions; however, Premanand et al did not identify cell proliferation under moderately high glucose conditions. Notably, this phenomenon may be due to a particularity of this primary HREC culture. Furthermore, proliferation of primary cultured human umbilical vascular endothelial cells was investigated in the present study, and an opposite result to that of the proliferation of HRECs was obtained: Moderately high glucose conditions decreased cell proliferation in a glucose concentration-dependent manner. This was consistent with a previous study (20).

It was unexpected that moderately high glucose (15 $\mathrm{mM})$ but not high glucose $(30 \mathrm{mM})$ levels significantly triggered cell proliferation in HRECs. A previous study by our group showed that VEGF secretion was glucose concentration-dependent, unlike the proliferation results. This indicated that VEGF may not affect the proliferation of HRECs, but may be a possible explanation for the correlation between glucose concentration and proliferation. In the case of moderately high glucose, which represents clinical hyperglycemia in untreated patients with diabetes, endothelial cells may develop certain degrees of tolerance to glucose toxicity. Therefore, cell proliferation induced by VEGF appeared to be dominant. By contrast, the high glucose conditions exceeded the physiologically tolerable range. Glucose toxicity may have been predominant, so that proliferation was not observed.

Since its seminal discovery by Kishimoto et al (21), PKC has gained increasing attention in the biomedical field due to its extensive role in cell signaling, ion channel regulation, cell proliferation and differentiation as well as tumorigenesis. The PKC isoforms display distinct localization and expression in different tissues and cells. Information regarding expression of PKC isoforms in eye tissues has been somewhat inconsistent. In the retinal tissue of rabbits, three isoforms, PKC $\alpha, \beta$ and $\gamma$, were identified (22). In addition, PKC $\alpha, \beta \mathrm{I}, \beta \mathrm{II}, \delta, \varepsilon$ and $\zeta$ were detected in the mouse retina (7). Moreover, PKC $\alpha, \beta \mathrm{I}, \beta \mathrm{II}, \varepsilon$ and $\delta$ were expressed in rat retina. In human retinal tissues, PKC $\alpha, \beta \mathrm{I}, \beta \mathrm{II}, \varepsilon, \delta, \theta, \zeta, \mathrm{l}$ and $\mu$ were detected in retinal pigment epithelial cells (23). However, few studies have focused on PKC isoforms in HRECs. Therefore, the expression and translocation of the most common six isoforms of PKC that have been previously identified in retinal tissues, PKC $\alpha, \beta \mathrm{I}, \beta \mathrm{II}, \varepsilon, \delta$ and $\zeta$, were examined in the present study. To the best of our knowledge, the present study was the first to demonstrate the expression of five PKC isoforms, including PKC $\alpha, \beta \mathrm{I}, \beta \mathrm{II}, \delta$ and $\varepsilon$, in primary cultured HRECs, while PKC $\zeta$ was not identified. Under the same experimental conditions, all six isoforms of PKC were identified in rat brain tissue, which supports the results of the present study.

The present study aimed to examine the translocation of PKC isoforms triggered by high glucose, moderately high glucose and hypoxic conditions in primary cultured HRECs. Cell fractionation and immunofluorescence imaging demonstrated that membrane PKC $\delta$ levels were markedly increased in the moderately high glucose group; however, not in the high glucose group. Thus, it was hypothesized that moderately high glucose and high glucose levels had discrepant effects on cell proliferation. Previous studies have reported that PKC $\delta$ was widely distributed in various organs and cell types, and that the excessive activation of PKC $\delta$ may be associated with tumor growth, angiogenesis and neutrophil adhesion (24-26). In primary cultured HRECs, the proliferation caused by moderately high glucose levels was prevented by rottlerin, an inhibitor of PKC $\delta$. Ro32-0432, which is capable of inhibiting PKC $\alpha, \beta$ I and $\varepsilon$, exhibited only minor significant effects on cell proliferation. These findings suggest that PKC $\delta$ contributed to cell proliferation under moderately high glucose conditions.

The pathogenesis of diabetic retinopathy is a complex process involving multiple factors, among which chronic activation of PKC has been deemed a prominent factor associated with vascular alterations, including increased permeability, contractility, extracellular matrix synthesis, cell growth, apoptosis and angiogenesis. Among PKC isoforms, previous studies have reported that PKC $\alpha, \beta, \delta$ and $\varepsilon$ were activated by hyperglycemia in retinal tissues $(27,28)$. Clinical trials have demonstrated positive results for diabetic non-proliferate retinopathy following the administration of a PKC $\beta$ II isoform inhibitor. This supports our findings in which PKC $\beta I I$ was not associated with the proliferation of primary cultured HRECs (i.e. proliferative retinopathy).

Although high glucose failed to trigger cell proliferation, it induced translocation of PKC $\alpha$ and $\varepsilon$. In previous studies, the distinct function and complicated interactions of PKC isoforms have been reported. For example, decreased PKC $\alpha$ expression levels resulted in a significant decrease in cell proliferation in human pigment epithelium cells (29). In addition, PKC $\delta$ is able to regulate PKC $\alpha$ activity (30). Moreover, treatment of human umbilical vein endothelial cells with VEGF resulted in the activation of PKC $\alpha$, but not PKC $\varepsilon$, which was associated with enhanced proliferation and angiogenesis (31). PKC $\varepsilon$ has been indicated to be cardioprotective as its activation was required and was sufficient to induce a preconditioning-like response. By contrast, PKC $\delta$ activation contributed to myocardial damage in ischemia/reperfusion (32). The same opposing roles of PKC $\varepsilon$ and $\delta$ have been reported for cerebral ischemia/reperfusion (33). Therefore, the interactions among $\operatorname{PKC} \alpha, \varepsilon$ and $\delta$ require further investigation in order to highlight the mechanisms by which high glucose concentrations do not cause proliferation in HRECs.

The present study revealed that the effects of hypoxia and moderately high glucose levels on the translocation of PKC isoforms were different, although they resulted in equal amounts of cell proliferation. Hypoxia may act through affecting VEGF expression via the increased binding of the active hypoxia inducible factor- $1 \alpha$ to the hypoxic response element of the VEGF promoter (34). Although PKC $\zeta$ attenuated hypoxia-induced proliferation of fibroblasts by regulating MAP kinase phosphatase-1 expression (35), PKC $\zeta$ was not expressed in the present study. Rottlerin, an inhibitor of PKC $\delta$, was capable of preventing cell proliferation caused by moderately high glucose levels, but not by hypoxia. Furthermore, PKC $\delta$ was not translocated under hypoxic conditions. These results suggest that PKC $\delta$ was not associated with cell proliferation caused by hypoxia. This conclusion is further supported by the fact that Ro32-0432, which inhibits several PKCs other than PKC $\delta$, did not affect cell proliferation at medium high glucose levels. 


\section{Acknowledgements}

This study was supported by the Project of National Ministry of Science and Technology (no. 2011ZX11101) and Guangdong Province (no. 2007A032702001).

\section{References}

1. Lu M, Kuroki M, Amano S, et al: Advanced glycation end products increase retinal vascular endothelial growth factor expression. J Clin Invest 101: 1219-1224, 1998.

2. Kern TS and Engerman RL: Capillary lesions develop in retina rather than cerebral cortex in diabetes and experimental galactosemia. Arch Ophthalmol 114: 306-310, 1996.

3. Agardh CD, Agardh E, Zhang $\mathrm{H}$ and Ostenson CG: Altered endothelial/pericyte ratio in Goto-Kakizaki rat retina. J Diabetes Complications 11: 158-162, 1997.

4. Crawford TN, Alfaro DV 3rd, Kerrison JB and Jablon EP: Diabetic retinopathy and angiogenesis. Curr Diabetes Rev 5: 8-13, 2009.

5. Das Evcimen $\mathrm{N}$ and King GL: The role of protein kinase $\mathrm{C}$ activation and the vascular complications of diabetes. Pharmacol Res 55: 498-510, 2007.

6. Steinberg SF: Structural basis of protein kinase C isoform function. Physiol Rev 88: 1341-1378, 2008.

7. Pedro G and George LK: Activation of protein kinase C isoforms and its impact on diabetic complications. Circ Res 106: 1319-1331, 2010.

8. Park JY, Takahara N, Gabriele A, et al: Induction of endothelin-1 expression by glucose: an effect of protein kinase $\mathrm{C}$ activation. Diabetes 49: 1239-1248, 2000.

9. Gao R, Zhu BH, Tang SB, et al: Scutellarein inhibits hypoxiaand moderately-high glucose-induced proliferation and VEGF expression in human retinal endothelial cells. Acta Pharmacol Sin 29: 707-712, 2008.

10. Lai P, Li T, Yang J, et al: Upregulation of stromal cell-derived factor 1 (SDF-1) expression in microvasculature endothelial cells in retinal ischemia-reperfusion injury. Graefes Arch Clin Exp Ophthalmol 246: 1707-1713, 2008.

11. Li X, Hahn CN, Parsons M, et al: Role of protein kinase C zeta in thrombin-induced endothelial permeability changes: inhibition by angiopoietin-1. Blood 104: 1716-1724, 2004.

12. Sakai H, Yamamoto M, Chiba Y, et al: Some different effect of PKC inhibitors on the acetylcholine, and endothelin-1-induced contractions of rat bronchial smooth muscle. Eur J Pharmacol 618: 58-62, 2009.

13. Wong $\mathrm{C}$ and Jin ZG: Protein kinase $\mathrm{C}$-dependent protein kinase D activation modulates ERK signal pathway and endothelial cell proliferation by vascular endothelial growth factor. J Biol Chem 280: 33262-33269, 2005.

14. Griger Z, Páyer E, Kovács I, et al: Protein kinase C- $\beta$ and $-\delta$ isoenzymes promote arachidonic acid production and proliferation of MonoMac-6 cells. J Mol Med 85: 1031-1042, 2007.

15. Kim JH, Kim JH, Jun HO, et al: Inhibition of protein kinase C attenuates blood-retinal barrier breakdown in diabetic retinopathy. Am J Pathol 176: 1517-1524, 2010.

16. Wilkinson SE, Parker PJ and Nixon JS: Isoenzyme specificity of bisindolylmaleimides, selective inhibitors of protein kinase C. Biochem J 294: 335-337, 1993.

17. Ding M, Huang C, Lu Y, et al: Involvement of protein kinase C in crystalline silica-induced activation of the MAP kinase and AP-1 pathway. Am J Physiol Lung Cell Mol Physiol 290: L291-L297, 2006.
18. Eitel I, Hintze S, de Waha S, et al: Prognostic impact of hyperglycemia in nondiabetic and diabetic patients with ST-elevation myocardial infarction insights from contrast-enhanced magnetic resonance imaging. Circulation: Cardiovascular Imaging 5: 708-718, 2012.

19. Premanand C, Rema M, Sameer MZ, et al: Effect of curcumin on proliferation of human retinal endothelial cells under in vitro conditions. Invest Ophthalmol Vis Sci 47: 2179-2184, 2006.

20. Rojas S, Rojas R, Lamperti L, et al: Hyperglycaemia inhibits thymidine incorporation and cell growth via protein kinase $\mathrm{C}$, mitogen-activated protein kinases and nitric oxide in human umbilical vein endothelium. Exp Physiol 88: 209-219, 2003.

21. Kishimoto A, Takai Y and Nishizuka Y: Activation of glycogen phosphorylase kinase by a calcium-activated, cyclic nucleotide-independent protein kinase system. J Biochem 82: 1167-1172, 1977.

22. Osborne NN, Barnett NL, Morris NJ, et al: The occurrence of three isoenzymes of protein kinase $\mathrm{C}$ (alpha, beta and gamma) in retinas of different species. Brain Res 570: 161-166, 1992.

23. Yu KM, Ma P, Ge J, et al: Expression of protein kinase C isoforms in cultured human retinal pigment epithelial cells. Graefes Arch Clin Exp Ophthalmol 245: 993-999, 2007.

24. Keshamouni VG, Mattingly RR and Reddy KB: Mechanism of $17-\beta$-estradiol-induced Erk1/2 activation in breast cancer cells. A role for HER2 and PKCס. J Biol Chem 277: 22558-22565, 2002.

25. Abbas T, White D, Hui L, et al: Inhibition of human p53 basal transcription by down-regulation of protein kinase $\mathrm{C} \delta$. J Biol Chem 279: 9970-9977, 2004.

26. Steinberg SF: Distinctive activation mechanisms and functions for protein kinase C delta. Biochem J 384: 449-459, 2004.

27. Inoguchi $\mathrm{T}$, Battan R, Handler E, et al: Preferential elevation of protein kinase $\mathrm{C}$ isoform beta II and diacylglycerol levels in the aorta and heart of diabetic rats: differential reversibility to glycemic control by islet cell transplantation. Proc Natl Acad Sci USA 89: 11059-11063, 1992.

28. Idris I, Gray S and Donnelly R: Protein kinase C activation: isozyme-specific effects on metabolism and cardiovascular complications in diabetes. Diabetologia 44: 659-673, 2001.

29. Gao Q, Tan J, Ma P, et al: PKC alpha affects cell cycle progression and proliferation in human RPE cells through the downregulation of p27kip1. Mol Vis 15: 2683-2695, 2009.

30. Murakami M, Horowitz A, Tang S, et al: Protein kinase C (PKC) delta regulates PKC alpha activity in a Syndecan-4-dependent manner. J Biol Chem 277: 20367-20371, 2002.

31. Wellner M, Maasch C, Kupprion C, et al: The proliferative effect of vascular endothelial growth factor requires protein kinase C-alpha and protein kinase C-zeta. Arterioscler Thromb Vasc Biol 19: 178-185, 1999.

32. Bright R and Mochly-Rosen D: The role of protein kinase C in cerebral ischemic and reperfusion injury. Stroke 36: 2781-2790, 2005.

33. Murriel CL and Mochly-Rosen D: Opposing roles of delta and epsilon PKC in cardiac ischemia and reperfusion: targeting the apoptotic machinery. Arch Biochem Biophys 420: 246-254, 2003.

34. Aiello LP, Northrup JM, Keyt BA, et al: Hypoxic regulation of vascular endothelial growth factor in retinal cells. Arch Ophthalmol 113: 1538-1544, 1995.

35. Short MD, Fox SM, Lam CF, et al: Protein kinase $\mathrm{C} \zeta$ attenuates hypoxia-induced proliferation of fibroblasts by regulating MAP kinase phosphatase-1 expression. Mol Biol Cell 17: 1995-2008, 2006. 